Revista Destaques Acadêmicos, Lajeado, v. 12, n. 1, 2020. ISSN 2176-3070

DOI: http://dx.doi.org/10.22410/issn.2176-3070.v12i1a2020.2310

http://www.univates.br/revistas

\title{
COACHING E LIDERANÇA NO SETOR BANCÁRIO: ESTUDO EM UMA AGÊNCIA DE UM BANCO PÚBLICO
}

\author{
Adriano Valar ${ }^{1}$, Nilva Rech Valar², Flávia Camargo Bernadi ${ }^{3}$, \\ Uiliam Hahn Biegelmeyer ${ }^{4}$, Maria Emilia Camargo ${ }^{5}$, Maiara Silva das Neves ${ }^{6}$
}

\begin{abstract}
Resumo: A liderança tem um papel estratégico, pois cabe a ela transmitir os princípios e valores que regem a organização, facilitando a adaptação e a integração dos funcionários, além de conceber e articular as metas que colocam as pessoas acima das preocupações individuais. $\mathrm{O}$ estilo de liderança praticado pelo líder pode incentivar a realização das atividades ou, pelo contrário, pode promover a competição negativa e desmotivar a equipe, sendo que, a falta de comprometimento prejudica a performance da empresa. Nesse sentido, esse estudo tem como objetivo identificar a importância do coaching e da liderança no desenvolvimento da equipe (funcionários e gestores) do segmento bancário em uma agência do setor público da Serra Gaúcha. A metodologia do estudo consiste em uma pesquisa descritiva, com abordagem quantitativa, por meio do uso de questionário estruturado, aplicado a cem por cento da equipe. Os resultados da pesquisa evidenciam que mais da metade dos funcionários entrevistados desconhece o coaching e a sua aplicação na prática. O estudo também evidencia que a maioria dos entrevistados não acredita que um processo de coaching influencie no atingimento das metas, por outro lado, a maioria mostra concordância sobre a necessidade de investimentos por parte da instituição bancária para a formação e o desenvolvimento de líderes.
\end{abstract}

Palavras-chave: Coaching. Equipe. Liderança. Resultados.

1 Especialista em Gestão de Pessoas.

2 Especialista em Gestão de Pessoas.

3 Mestre em Administração.

4 Doutor em Administração.

5 Doutora em Engenharia de Produção.

6 Bacharel em Administração. 


\section{INTRODUÇÃO}

Um dos grandes desafios de um líder numa instituição financeira pública é conseguir que os integrantes de sua equipe estejam em sintonia com os interesses do banco, felizes e determinados a darem o melhor de si para atingirem as metas estabelecidas.

No contexto atual, os funcionários estão sempre trabalhando sob pressão, visto a quantidade de metas e o número de clientes a serem atendidos. Da mesma forma, a instituição bancária apresenta um ambiente competitivo e, por se caracterizar como ente público, diferencia-se das demais instituições pela sua importante função social para os governantes municipais e estaduais para com as suas respectivas políticas econômicas. No setor público uma regra elementar é a transparência, ou seja, toda equipe deve atuar de forma correta e ainda ter visão sistêmica. Assim, todos os funcionários devem ter acesso aos manuais operacionais e o conhecimento dos produtos e serviços que serão oferecidos aos clientes, bem como os fundamentos estratégicos do banco (Missão, Visão e Valores) e também saber o que querem fazer: os motivos que os levam a trabalhar na área comercial quando são recrutados, e ainda, se desejam atuar no atendimento das pessoas físicas ou jurídicas.

A partir dessa breve contextualização, cabe ressaltar a importância de cada pessoa da equipe entender o seu papel na instituição bancária, bem como é possível desenvolver o aconselhamento de carreira de forma estratégica e individualizada para que se tenha equilíbrio entre os interesses da organização e dos indivíduos. Para que isso ocorra é possível desenvolver um processo de coaching de modo individual, incluindo fatores relacionados ao negócio (FREAS, 2003).

Outra, não menos relevante, é a valorização profissional. Todos os funcionários de uma empresa devem se sentir importantes, que efetivamente sejam ouvidos e que seus posicionamentos sejam levados em conta nas tomadas de decisões, isto é, que realmente se atue como uma equipe e não como executores dos serviços ou "grupo de pessoas" (BRUM, 2017).

Consoante a isso, Cortella (2015) acrescenta que um colaborador não se mantém na empresa somente pela remuneração, mas sua permanência também considera o significado do trabalho, o bem-estar que sente quando seu trabalho é valorizado e quando percebe ali a possibilidade de um futuro conjunto. Uma empresa que não oferece no dia a dia condições de reconhecimento, quebra esse equilíbrio.

Os gestores das instituições bancárias geralmente enfatizam que os funcionários devem estar motivados, serem proativos e engajados com o que pretendem desenvolver para que possam crescer profissionalmente e pessoalmente na instituição. Aliado ao crescimento dos profissionais, os gestores também se preocupam em como desenvolver o melhor atendimento aos clientes. De modo geral, os funcionários do segmento bancário têm ótimas 
oportunidades de desenvolvimento de suas carreiras, porém, apesar de ocuparem cargos excelentes com salários compatíveis, algumas vezes não se sentem realizados no ambiente de trabalho, devido ao contexto de pressões exercidas pela competitividade, concorrência e pela busca por resultados (AGLIARDI, 2016).

A partir do cenário competitivo, destaca-se também que os gestores da agência têm papel importante no desenvolvimento de seus liderados. Desta forma, atuar como líder coach passa a ser uma necessidade no dia a dia dos gestores do segmento bancário.

Diante dessa perspectiva, esse estudo de caso apresenta como problema: Como o coaching e a liderança podem ser aplicados em uma agência bancária da Serra Gaúcha para o desenvolvimento da equipe e o atingimento das metas?

Para atender ao questionamento, tem-se como objetivo geral identificar a percepção dos gestores e funcionários da agência sobre a importância do processo de coaching e da liderança para o desenvolvimento da equipe e o atingimento das metas.

Para atingir o objetivo geral têm-se os objetivos específicos, que são:

a) Compreender a importância do coaching e da liderança no setor bancário para o desenvolvimento das carreiras dos funcionários.

b) Realizar pesquisa com os funcionários da agência bancária.

Para tanto, a metodologia de pesquisa aplicada foi de natureza descritiva e quantitativa, por meio de estudo de caso, sendo que a coleta dos dados foi realizada por intermédio de questionário estruturado, em que os participantes apresentaram a sua percepção sobre as principais indagações relativas ao tema e especificaram o seu nível de concordância com uma afirmação.

Este artigo é composto em três partes: desenvolvimento do levantamento de literatura referente ao tema (revisão bibliográfica); um estudo de caso dentro da referida agência; e a análise dos resultados obtidos. Por fim, têm-se as considerações finais, na qual são apresentadas as conclusões do estudo, as limitações da pesquisa, bem como as recomendações para estudos futuros.

\section{REFERENCIAL TEÓRICO}

O referencial teórico contempla a delimitação do tema e consiste em uma ampla revisão teórica através de artigos e livros com as mais recentes obras científicas disponíveis que tratam do assunto. Portanto, o referencial apresenta uma breve abordagem sobre o setor bancário e as suas particularidades, definições de coaching e liderança e coaching para líderes no setor bancário. 


\subsection{Setor bancário e suas particularidades}

Uma preocupação fundamental que deve permear a rotina dos funcionários do setor bancário é a forma de atendimento aos clientes, pois a qualidade desse atendimento reflete diretamente no relacionamento e na satisfação do cliente. Um atendimento executado de forma errônea pode provocar o registro de reclamações na própria instituição ou em órgãos externos. Além disso, um banco é regido por metas e, portanto, todos devem exercer o papel de atendimento e vendas para que as metas sejam atingidas.

$\mathrm{O}$ atendimento executado em agências bancárias envolve uma venda transacional, na qual o atendente procura sensibilizar e convencer o cliente no primeiro contato, utilizando-se, por exemplo, de argumentos emocionais. Nesse caso, é importante lembrar que nem sempre o vendedor terá uma segunda chance para oferecer o seu produto ou serviço, então deve ser assertivo (GERHARDT, 2012).

Em paralelo a isso, todos os líderes do segmento bancário devem conhecer o potencial de cada funcionário da equipe para alocá-lo no local correto e obter a motivação dele, criando condições para o aperfeiçoamento contínuo, o desempenho e o bem estar de cada um, garantindo assim o melhor atendimento ao cliente.

Lembrando sempre que a motivação é uma porta que se abre de dentro para fora, é um processo que começa na seleção das pessoas. Geralmente, a motivação baseia-se em dois pilares: necessidade e paixão. Se você gosta, ama o que faz, vai querer melhorar sempre. Ainda é preciso compreender que a disposição de uma equipe, o entendimento e a colaboração entre os funcionários podem ser mais decisivos que o brilho individual (BERNARDINHO, 2006).

Quando se analisa as ocorrências registradas nas instituições financeiras, verifica-se que muitas dependem primordialmente do atendimento aos clientes (comportamento do funcionário, recusa de atendimento e "venda casada") e outras denotam a necessidade de revisar a maneira como se oferece e/ou se vende alguns dos principais produtos e serviços (Cartão de Crédito, Cesta de Serviços/Tarifas e Seguros).

A partir dessa breve caracterização, observa-se que o processo de coaching, dentro de uma instituição financeira pública pode ser fundamental para capacitar a equipe e aplicar os conceitos de liderança, organizando as pessoas dentro da própria equipe para que atuem na sua área de afinidade e não por acomodação, sendo assim, o gerente deve atuar como um Leader Coach, fazendo com que os funcionários sejam consultores e não vendedores, ou seja, oferecer o produto e/ou serviço adequado para cada perfil de cliente.

De acordo com Castro (2013), as empresas bem-sucedidas são as quais reconhecem a importância e investem nos seus funcionários, colocando-os no seu devido lugar, como importantes e decisivos para o crescimento profissional e a lucratividade da instituição financeira. 
Marques (2013) salienta que um líder consegue compreender as necessidades da equipe contribuindo para o desenvolvimento profissional de cada colaborador. Também acredita que para o grupo o Leader Coach deve ser um exemplo a ser seguido.

Outro desafio que pode ser alcançado por meio do processo de coaching é o entendimento sobre os valores, cultura e ética dos funcionários para que estejam alinhados com os princípios do banco, tema que tem crescido no Brasil e no exterior e, principalmente, nas instituições financeiras. Dessa forma, a empresa atingirá melhores resultados e conquistará clientes fiéis e que se identificam com o Banco (GARBELINI, 2016).

$\mathrm{Na}$ agência bancária em estudo, o atendimento a qualquer cliente precisa estar pautado em quatro pilares: Cortesia, Transparência, Eficiência e Disponibilidade. Conhecê-los e atuar em consonância com suas diretrizes é determinante para o sucesso profissional, para atingir a satisfação dos clientes e garantir o resultado financeiro.

Em complemento a isso, uma equipe de alta performance é aquela que tem metas compartilhadas, apresenta uma noção clara das prioridades, atua de forma honesta e íntegra, fornece feedbacks, tem total disponibilidade para falar abertamente, todos os participantes têm um entendimento e uma visão sistêmica, sendo capazes de substituir uns aos outros sem problemas de adaptações, baseados na confiança, capacidade e boa vontade de todos (MARQUES, 2013).

Nas agências bancárias há funcionários dos mais variados perfis profissionais, há diferentes formações e experiências, e todos devem ter o objetivo de oferecer um atendimento de qualidade e aprofundar o relacionamento com os clientes. Cabe esclarecer que no banco, define-se cliente como toda pessoa física ou jurídica, que se apresenta em agências e pontos de atendimentos ou entra em contato por qualquer local de interação, podendo fazer parte ou não de uma carteira de clientes diferenciados. Tal definição informa que cliente também é a pessoa que interage com a instituição por qualquer natureza, até mesmo em um centro cultural ou em um evento esportivo ou social. Ou seja, qualquer pessoa pode ser um cliente do banco, por isso todos devem estar preparados para prestar um atendimento de excelência.

\subsection{Definições de coachiing e liderança}

Segundo o dicionário Aurélio (2010), competência é a qualidade de quem é capaz de apreciar e resolver certo assunto, fazer determinada coisa; capacidade, habilidade, aptidão, idoneidade. Assim, nos tempos atuais temse uma maior adesão ao uso dessa teoria, pois cada vez mais os funcionários precisam adquirir conhecimentos para atenderem o exigente mercado de trabalho. Nessa perspectiva, percebe-se que o coaching pode auxiliar no desenvolvimento e/ou aquisição de novas competências. 
Para tanto, é importante compreender o que é coaching e como pode ser aplicado em agências bancárias do setor público. Lotz e Gramms (2014) argumentam que coaching é um processo que estimula reflexões para potencializar o desempenho de um indivíduo, promovendo o desenvolvimento pessoal e/ou profissional.

Na percepção de Marques (2013) o coaching visa aumentar o desempenho dos indivíduos, resultado em efeitos positivos. Para que isso ocorra, o processo contempla uma metodologia que utiliza ferramentas e técnicas aplicadas por um profissional capacitado e habilitado para exercer esse papel. Em resumo, o objetivo do coaching é sair de um ponto atual para chegar a outro ponto e/ou estado desejado.

O coaching busca a solução dentro de cada indivíduo e está baseado em conduzir o indivíduo para a solução através de perguntas, ou seja, é preciso conduzir o cliente para a solução (sem oferecer a solução) que atenda as suas necessidades. O coach utiliza ferramentas com o propósito de estimular o coachee a observar a situação de acordo com uma nova perspectiva (GERHARDT, 2012; LOTZ; GRAMMS, 2014).

É possível que as pessoas não saibam como e o que precisam para aumentar seus conhecimentos e competências. Desenvolver competências comportamentais abrange as crenças individuais e o coach é preparado para derrubar essas crenças que impedem o funcionário de atingir uma alta performance (KRAUSPENHAR; MARQUES, 2015). Além disso, o coaching contribui para que as pessoas enxerguem outras possibilidades, permitindo alterar o padrão de escolhas e obter resultados diferentes (LOTZ; GRAMMS, 2014).

De acordo com Krauspenhar e Marques (2015), algumas pessoas se perdem em seus objetivos e foco, acomodam-se e dão importância a coisas paralelas, deixando de se capacitar. Todo esse processo de mudança precisa partir da vontade do funcionário e, caso ele não veja importância em mudar, desistirá facilmente. Krauspenhar e Marques (2015 complementam que o coaching desenvolve o autoconhecimento que, por sua vez, ajuda a identificar as principais habilidades de cada indivíduo e, com isso, fortalecer seus pontos fortes.

O mercado profissional está demonstrando que a função do bancário daqui para frente vai ser diferente. Os bancários terão que atuar como empreendedores e desenvolverão funções diferentes, basta analisar o uso de tecnologias que as instituições bancárias vêm incorporando. Quem resistir ficará para trás. Todos terão que aceitar e caminhar junto com a evolução. Nesse contexto de novas tecnologias, os líderes passam a ter uma importância ainda maior.

Conforme a percepção de Franco (2015), quando os líderes estão despreparados, os funcionários entram em conflito ou se acomodam como um 
mecanismo de defesa. Sem inovação e crescimento a equipe e o banco ficam estagnados e passam a correr grandes riscos no mercado altamente competitivo.

Os líderes devem ser transparentes e atuar como treinadores. No mundo de hoje não é possível esconder conhecimento. Bernardinho (2006, p. 114) enfatiza que o líder deve dar o exemplo por meio de suas atitudes e ações, inspirando e influenciando as pessoas para que façam a coisa certa, de preferência com entusiasmo para atingir um objetivo comum. Cabe estabelecer a diferença entre coaching e liderança, e compreender o quanto essas duas técnicas e ferramentas estão relacionadas e como devem ser utilizadas de forma complementar. Marques (2013) diz que a liderança é uma habilidade que está relacionada com a motivação e com a influência dos liderados para que atinjam os resultados desejados, considerando sempre o comportamento ético e positivo.

Goldsmith, Lyons e Freas (2003) consideram a liderança como um relacionamento, onde há um vínculo e um depende do outro. Os autores também dizem que liderança não tem um número certo para acontecer, o relacionamento pode ocorrer com um ou com mil pessoas.

De acordo com os autores e conceitos anteriores, a crise no mundo dos negócios não é tão grave quanto à dificuldade de encontrar líderes emocionalmente capacitados, o denominado leader coach que, com as suas habilidades, conhecimentos e experiências, consegue formar uma equipe de alta performance e motivada para atingir os resultados planejados, além de administrar essa equipe com maestria (BIEGELMEYER ET AL,2016).

Com a carência de liderança, não é possível formar equipes ou as mesmas são desfeitas, pois o mercado está mais preocupado em formar profissionais eficientes (técnicos e gerentes) do que líderes eficazes (AMARAL ET AL,2019). Por outro lado, Charan (2008) pontua que mesmo tendo poucos líderes competentes no mercado, há muitos profissionais que podem ser desenvolvidos. ".

Por outro lado, as empresas, independente do segmento, podem desenvolver todos os líderes necessários, a partir do momento em que possuem um conhecimento claro sobre o que um líder é e o que é necessário para desenvolvê-lo, a empresa pode tomar ações para criar um banco de líderes (CHARAN, 2008).

Uma das formas de desenvolver líderes é investir em coaching, capacitando os líderes para que atuem como leader coach. Para Lotz e Gramms (2014o primeiro passo de uma liderança baseada em coaching é romper a cultura de vitimização, fazendo com que a equipe se torne mais pró-ativa em seus pensamentos e escolhas e, consequentemente, impactando nos resultados.

Raramente os funcionários de uma agência bancária sem a orientação de um leader coach se tornarão uma equipe de alta performance que trabalha alinhada aos princípios do banco, focando nos resultados e metas. O leader 
coach implementa ferramentas e formas de trabalhar inovadoras, sempre com o objetivo de acrescentar valor aos liderados, levando-os rumo à alta performance com melhorias contínuas e consistentes.

\subsection{Coaching para líderes do setor bancário}

Atualmente, no mundo dos negócios, fala-se menos na formação de um generalista e mais na formação de um multiespecialista. É menos um funcionário voltado para uma visão apenas genérica das atividades, mas ele ganha autonomia para construir novas competências. A busca por excelência e resultados tornou-se prioridade para os líderes, deve-se otimizar recursos e atuar com custos reduzidos (GOMES, 2015).

Um líder que se destaca é o que trabalha em favor da instituição e dos funcionários, tem relações positivas, desenvolve talentos e conduz a equipe aos resultados por sua influência, valorizando o potencial de cada um e buscando a excelência nos resultados (GOLDSMITH; LYONS; FREAS, 2003).

De acordo com Castro (2013), é comum ouvir que aquele funcionário é um líder nato. Na verdade, muitas pessoas têm o dom de congregar, somar esforços e liderar. Todavia, a liderança deve ser permanentemente cultivada pelo líder de forma contínua, deve empreender ações reflexivas sobre seus atos em relação aos seus funcionários, ao mercado e aos objetivos e às necessidades da instituição. É preciso compreender, enquanto líder, que o banco é maior do que seu ego e suas aspirações pessoais e que suas funções estão a serviço da instituição.

O processo de coaching é um diferencial para os líderes que buscam autonomia em seus funcionários. Gomes (2015) afirma que o coaching visa desenvolver, transformar e apresentar resultados. $O$ autor destaca que $o$ coaching atua com técnicas efetivas de aumento de performance, busca metas, objetivos e sonhos, ensina a pensar diferente, ampliando a visão e permitindo o crescimento na carreira.

O processo de coaching produz melhorias na performance dos funcionários e do banco, um crescimento veloz tanto no âmbito pessoal, quanto no profissional, um relacionamento saudável entre líderes e liderados e a possibilidade de ter uma equipe de alta performance para o alcance das metas e outros objetivos. Para que isto aconteça, é necessário o acompanhamento de um coach preparado para que os coachees estejam comprometidos com o processo (DIAS et. al., 2015).

Ainda conforme Dias et. al. (2015), o método do coaching acelera os resultados, proporciona um aumento na autoestima dos funcionários estimulando-os a executarem ações em outras áreas, contribuindo para a melhoria na qualidade de vida, diminuindo o estresse e abrindo caminho para melhor aproveitar as coisas positivas que a vida oferece. 


\section{METODOLOGIA DA PESQUISA}

O presente estudo partiu de suposições dos pesquisadores sobre o caso, uma vez que ambos atuam no segmento bancário em instituições públicas. Caracteriza-se como um estudo de caso, pois considera a realidade específica de uma agência bancária situada na Serra Gaúcha. O estudo de caso é muito utilizado quando se tem questões "como" e "por que", e o enfoque está sobre um fenômeno contemporâneo no contexto da vida real (YIN, 2010).

A metodologia contempla a pesquisa descritiva, que visa descrever as características de determinada população ou fenômeno ou o estabelecimento de relações entre variáveis. Envolve o uso de técnicas padronizadas de coleta de dados: questionário e observação sistemática. Assume, em geral, a forma de levantamento (PRODANOV; FREITAS, 2013).

Para coletar os dados, utilizou-se de questionário composto por 10 (dez) questões. O questionário foi construído com base no referencial teórico e passou pela validação de um especialista na área e por um pré-teste. No processo de pré-teste os questionários devem ser aplicados a uma pequena amostra da população para identificar e eliminar possíveis problemas (RODRIGUES, 2015).

O tipo de estudo descritivo utilizado na pesquisa foi o levantamento de campo. No método de levantamento de campo as informações foram obtidas através de perguntas aos funcionários. A abordagem de pesquisa aplicada foi de natureza quantitativa. Pesquisa quantitativa considera que tudo pode ser quantificável, o que significa traduzir em números opiniões e informações para classificá-las e analisá-las. Requer o uso de recursos e de técnicas estatísticas (PRODANOV; FREITAS, 2013).

A coleta dos dados foi feita por meio de um questionário, em que os participantes puderam responder as questões em Escala Likert e as questões fechadas (sim ou não). Os dados foram coletados no período de 19 a 23 de fevereiro de 2018, sendo que contemplou o censo da agência bancária, situada em Caxias do Sul no Rio Grande do Sul. O censo é uma coleta realizada sobre populações que possuem uma sequência de estruturação bastante utilizada nas pesquisas descritivas: especificação dos objetivos; operacionalização dos conceitos e das variáveis; elaboração do instrumento de coleta de dados; préteste do instrumento; seleção de amostra; coleta e verificação dos dados; análise e interpretação dos dados; e, apresentação dos resultados (PRODANOV; FREITAS, 2013). Por fim, realizou-se a análise dos dados coletados na pesquisa quantitativa, montando tabelas e gráficos para melhor visualização dos resultados.

\section{ANÁlise DOS RESULTADOS}

Esta etapa contempla a análise das informações coletadas junto aos funcionários da agência bancária, sendo que a partir das respostas analisouse, com base nas categorias pré-estabelecidas: o perfil dos respondentes, o 
conhecimento sobre coaching e a relação entre coaching versus liderança. $\mathrm{O}$ questionário foi respondido pelos 19 (dezenove) funcionários, totalizando $100 \%$ (cem por cento).

\subsection{Perfil dos respondentes}

A partir do Gráfico 1, verifica-se que $68 \%$ (sessenta e oito por cento) dos entrevistados são do gênero feminino. O gráfico 2 mostra a faixa etária, sendo que a predominante é acima de 35 anos. Por sua vez, o gráfico 3 apresenta que $74 \%$ (setenta e quatro por cento) dos entrevistados não tem função gerencial.

Gráfico 1 - Gênero dos Entrevistados

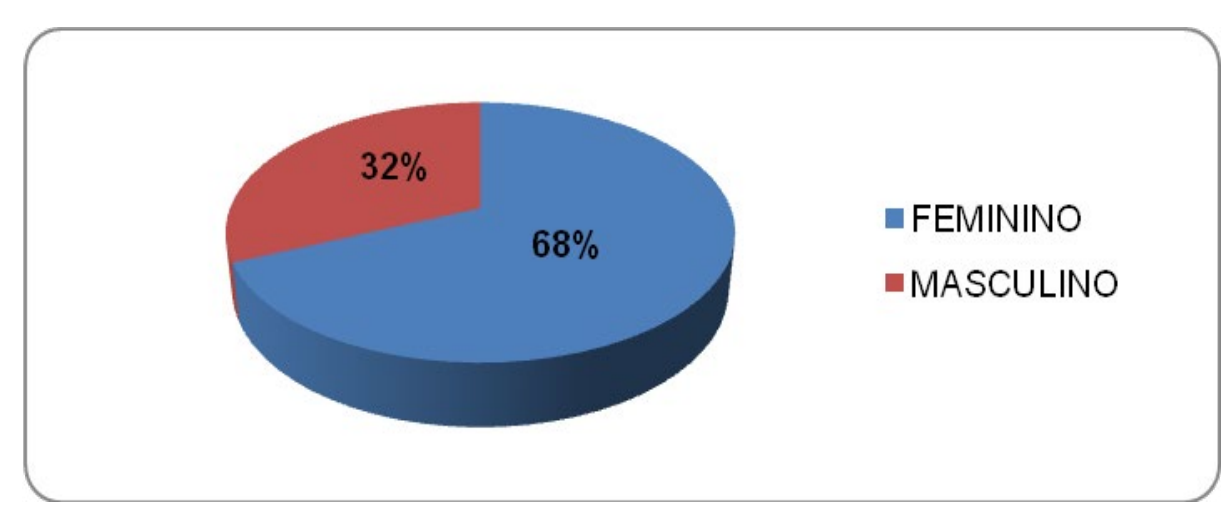

Fonte: elaborado pelos pesquisadores (2018)

Gráfico 2 - Faixa Etária dos Entrevistados

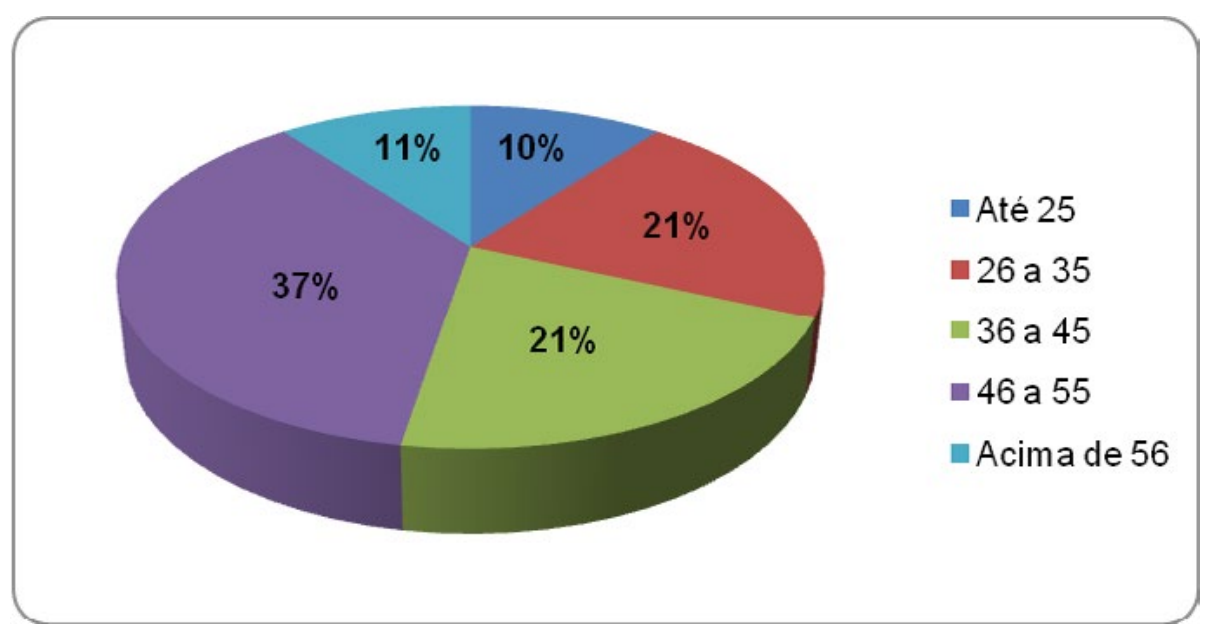

Fonte: elaborado pelos pesquisadores (2018) 
Gráfico 3 - Função Gerencial

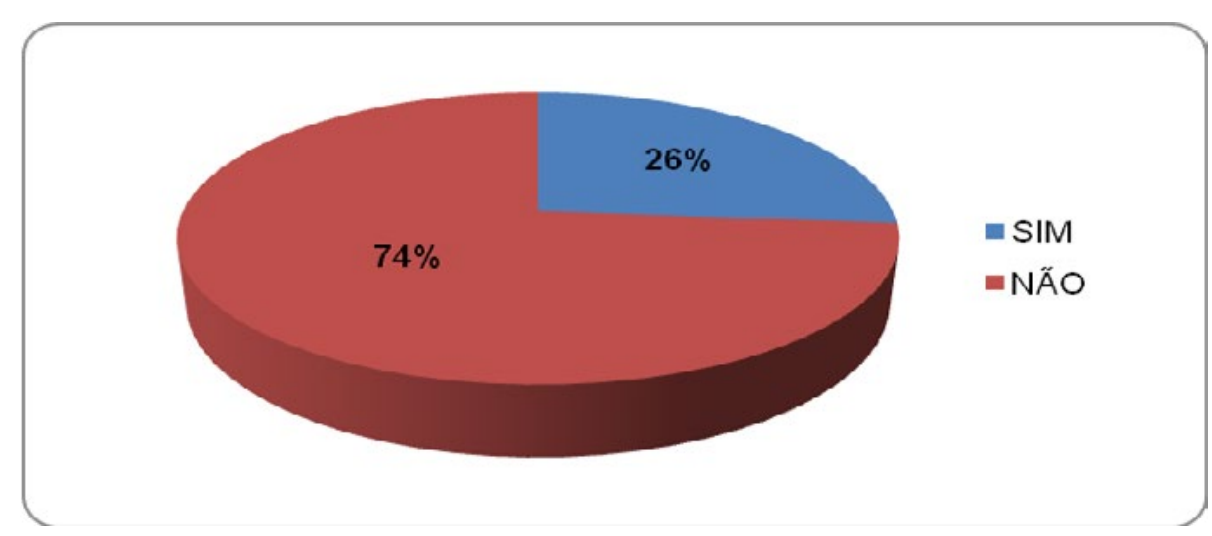

Fonte: elaborado pelos pesquisadores (2018)

\subsection{Conhecimento sobre coaching}

Verificou-se que dos 19 (dezenove) entrevistados, 11 (onze) nunca participaram de um processo de coaching. Outro ponto importante é que foi possível constatar que oito funcionários não sabem o que é coaching. Entretanto, 90\% (noventa por cento) dos entrevistados acredita que um processo de coaching irá ajudá-los a atingir as metas estipuladas pelo banco.

Gráfico 4 - Participação em Processos de Coaching

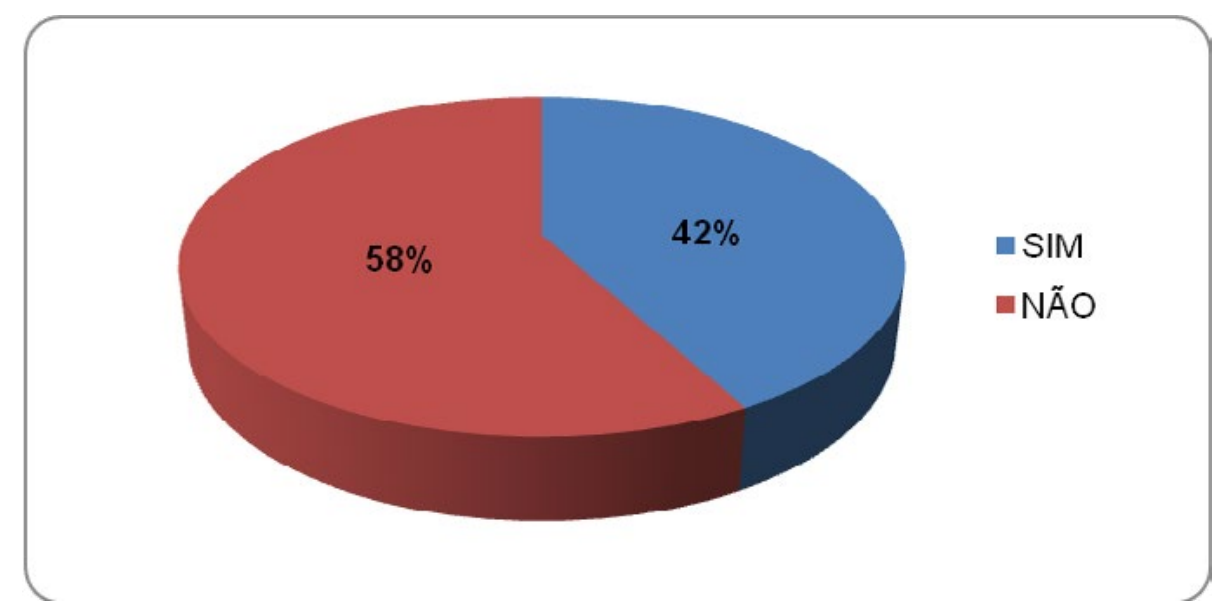

Fonte: elaborado pelos pesquisadores (2018) 
Gráfico 5 - Conhecimento sobre Coaching

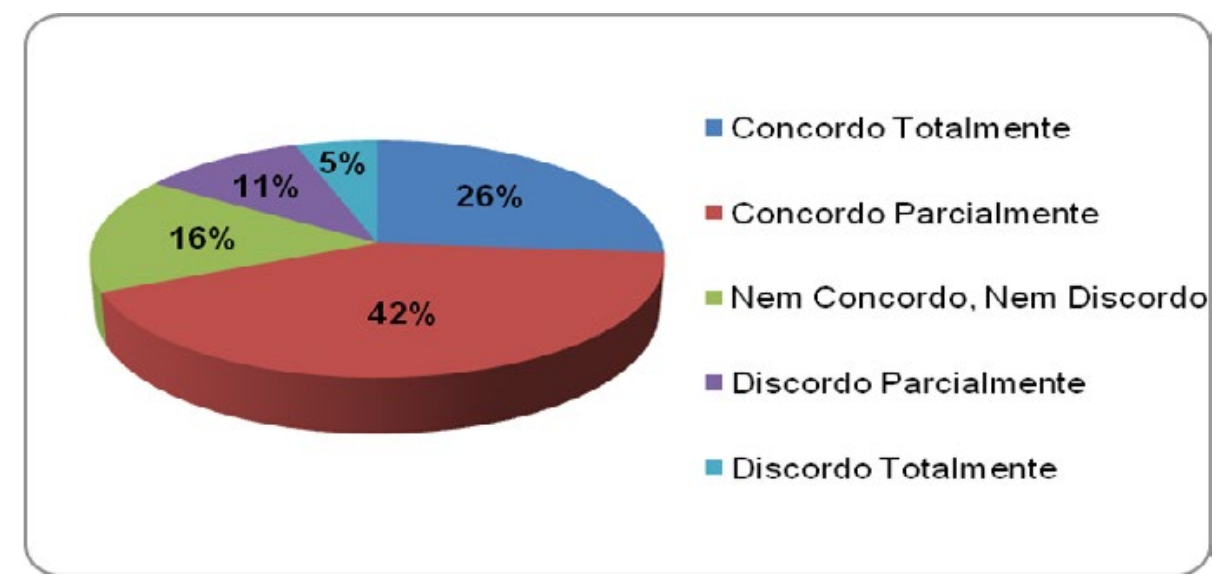

Fonte: elaborado pelos pesquisadores (2018)

Conforme mencionado no referencial teórico é preciso compreender o que é coaching e devido à proliferação do uso dessa técnica, muitas pessoas acabam desconhecendo o que significa e qual é o papel do coach.

Mesmo que nem todos conheçam sobre coaching, a maioria acredita que o coaching pode auxiliar no atingimento das metas conforme é possível observar no Gráfico 6 abaixo:

Gráfico 6 - Coaching versus Metas



Fonte: elaborado pelos pesquisadores (2018)

Nota-se nessa breve análise que os profissionais compreendem a importância de utilizar o coaching como uma forma de capacitar a equipe para que possam atingir os resultados desejados pelo banco. 


\subsection{Coaching versus liderança}

Nos Gráficos 7, 8 e 9, observa-se que as respostas foram semelhantes: a maioria dos entrevistados gostaria de aperfeiçoar os conhecimentos em uma formação de líderes através do processo de coaching. Também nesta análise, fica evidente que os entrevistados pretendem crescer na carreira profissional como leader coach para gerir equipes de alta performance.

Gráfico 7 - Interesse que o Banco invista na Formação de Líderes por meio do Coaching

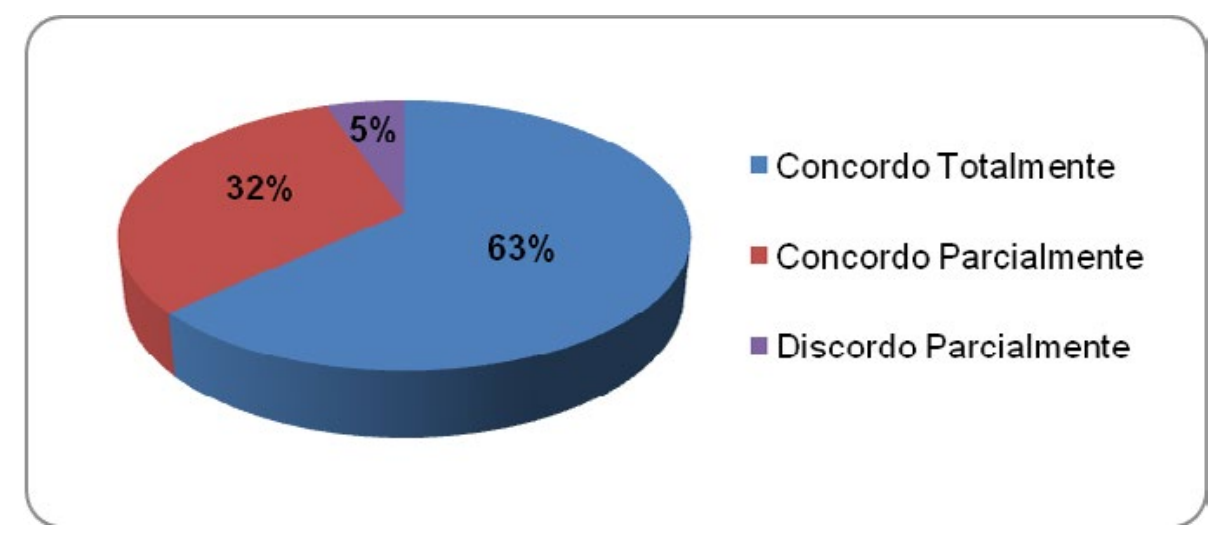

Fonte: elaborado pelos pesquisadores (2018)

Gráfico 8 - Interesse em Participar de um Processo de Coaching



Fonte: elaborado pelos pesquisadores (2018) 
Gráfico 9 - O Coaching pode Auxiliar no Atingimento das Metas

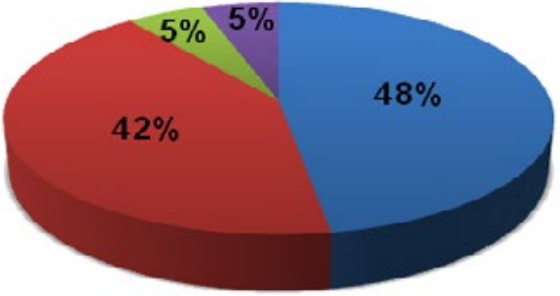

- Concordo Totalmente

a Concordo Parcialmente

ENem Concordo, Nem Discordo

- Discordo Parcialmente

Fonte: elaborado pelos pesquisadores (2018)

Segundo Marques (2012), o ambiente corporativo tem valorizado bastante um tipo de liderança que se alia ao coaching para potencializar o desenvolvimento das pessoas e os resultados dentro da empresa, esse tipo de líder é conhecido como leader coach.

Para a manutenção da sustentabilidade e a perpetuação das instituições, os líderes necessitam questionar seus hábitos de liderança. A mudança de cultura inicia-se no executivo, que ao refletir sobre seus hábitos de liderança e conseqüências para a instituição, passa a atuar e permitir o desenvolvimento da cultura coach. Com isso, evolui o seu comportamento de líder atuando no processo de coaching para a formação de uma equipe de alta performance.

\section{CONSIDERAÇÕES FINAIS}

Coaching e liderança são essenciais para o aumento de performance, seja de uma empresa, pessoa e/ou equipe. Assim, o objetivo inicial do artigo era identificar a percepção dos funcionários de uma agência bancária pública sobre o uso do coaching e práticas de liderança para o desenvolvimento de equipe e atingimento de metas. O propósito inicial do estudo foi atingido, porém percebeu-se também que há oportunidades para o desenvolvimento de estudos mais aprofundados nessa área.

Observou-se que, embora nem todos os entrevistados tenham vivenciado um processo de coaching e/ou até mesmo tenham um conhecimento claro sobre o que é coaching, a maioria percebe a importância de uma formação em coaching para o desenvolvimento de competências relacionadas à liderança e, mais do que isso, compreende o quanto o coaching pode auxiliar no atingimento das metas.

Cada pessoa tem um objetivo claro e definido sobre a sua carreira, então é preciso definir os caminhos para atingir os objetivos. Notou-se claramente através da fundamentação teórica a importância de ter um líder coach na instituição para auxiliar no crescimento da equipe e no atingimento dos resultados. A forma mais eficaz e eficiente de gerenciar a mudança é criá-la. Para que os funcionários atendam bem seus clientes em suas áreas de atuação é necessário planejar e programar um processo de 
coaching transparente e gradual, guiado por metas de curto, médio e longo prazo que servem como medidas de monitoramento da evolução dos funcionários e dos negócios realizados por eles.

Esse estudo apresenta algumas limitações, tais como o fato de contemplar a percepção de funcionários de uma única agência, que apresenta um número reduzido de funcionários. Por se tratar de um estudo de caso e não haver pesquisas realizadas anteriormente sobre o tema na agência em análise buscou-se o desenvolvimento de um instrumento que pudesse apresentar uma ideia da percepção atual dos bancários sobre a temática, porém nota-se que a pesquisa precisa ser ampliada.

Desta forma, esse trabalho foi apenas o início de uma pesquisa que poderá ser aprofundada. Sugere-se que o mesmo estudo seja aplicado em outras agências da mesma instituição bancária, assim como é possível desenvolver um estudo qualitativo para compreender melhor as respostas apresentadas nesse estudo com abordagem quantitativo. Outra possibilidade é estudar uma ferramenta de processo coaching adequada para ser aplicada com os funcionários, mensurando os resultados da aplicação prática e, caso seja comprovado que o processo seja realmente eficaz e eficiente na agência, que o mesmo seja replicado para que seja implementado em toda a rede de agências do banco em estudo.

\section{REFERÊNCIAS}

AGLIARDI, Amanda Pereira. Desenvolvimento de carreiras em agências bancárias através do coaching: um estudo de caso no Banco ABC. Disponível em:< www. admpg.com.br/2016/down.php?id=2186\&q=1>. Acesso em 25 de março de 2018.

AMARAL, Paola Reis do; MENDEL, Neusa Francisco; BIEGELMEYER, Uiliam Hahn; CAMARGO, Maria Emília, RECH ,Munique. A Influência do Líder Global no Ambiente Multicultural. Revista Inteligência Competitiva v9 n,1. 2019.

BERNARDINHO. Transformando Suor em Ouro. Rio de Janeiro: Sextante, 2006.

BIEGELMEYER,Uiliam Hahn; BRIDI, Cassiano; CARDOSO, Eduardo Luiz; CAMARGO, Maria Emília; CRACO, Tânia; GALELI, Ademar, The Behavior of the Carismatic Leader in the Catholic Church. International Journal of Current Research, v8, I 4, p 30115-30123. 2016.

BRUM, Analisa de Medeiros. Endomarketing estratégico: como transformar líderes em comunicadores e empregados em seguidores. São Paulo: Integrare, 2017.

CASTRO, Messias Mercadante de. O Gerenciamento da Vida Pessoal, Profissional e Empresarial. São Paulo: M.Books do Brasil, 2013.

CHARAN, Ram. O líder criador de líderes. Rio de Janeiro: Elsevier, 2008. 
CORTELLA, Mario Sergio. Qual é a tua obra?: inquietações propositivas sobre gestão, liderança e ética. Petrópolis: Vozes, 2015.

DIAS, André Renato Ferreira. et al. Coaching: aceleração de resultados. São Paulo: Ser Mais, 2015.

FERREIRA, Aurélio Buarque de Holanda Ferreira. Dicionário Aurélio da língua portuguesa. Curitiba: Positivo, 2010.

FRANCO, Rosina. et al. Coaching: aceleração de resultados. São Paulo: Ser Mais, 2015.

GARBELINI, Viviane Maira Penteado. Negociação e Conflitos. Curitiba: InterSaberes, 2016.

GERHARDT, Paulo M. T. Coaching de Vendas: Conduza seu cliente para a solução e venda mais. Cachoeirinha: Papel das Ideias, 2012.

GOLDSMITH, Marshall; LYONS, Laurence; FREAS, Alissa. Coaching: o exercício da liderança. Rio de Janeiro: Elsevier, 2003.

GOMES, Aline. et al. Coaching: aceleração de resultados. São Paulo: Ser Mais, 2015.

KRAUSPENHAR, Camila; MARQUES, Marcelino. et al. Coaching: aceleração de resultados. São Paulo: Ser Mais, 2015.

LOTZ, Erika Gisele; GRAMMS, Lorena Carmem. Coaching e mentoring. Curitiba: InterSaberes, 2014.

MARQUES, José Roberto. Leader Coach: Coaching como Filosofia de Liderança. São Paulo: Ser Mais, 2013.

MARQUES, José Roberto; CARLI, Edson. Coaching de Carreira: Construindo profissionais de sucesso. São Paulo: Ser Mais, 2012.

PRODANOV, Cleber Cristiano; FREITAS, Ernani Cesar de. Metodologia do trabalho científico: métodos e técnicas da pesquisa e do trabalho acadêmico. Novo Hamburgo: Feevale, 2013.

RODRIGUES, Airton. Pesquisa mercadológica. São Paulo: Pearson Education do Brasil, 2015.

YIN, Robert K. Estudo de caso: planejamento e método. Porto Alegre: Bookman, 2010. 